\title{
Retinal vascular disorders during pregnancy: An observational study
}

\author{
Rajendra P. Maurya ${ }^{1, *}$, Tanmay Srivastav ${ }^{2}$, Soni Chaudhary ${ }^{3}$, Priyanshi Awasthi ${ }^{4}$, Mamta Rajan $^{5}$ \\ 1,5 Assistant Professor, ${ }^{2}$ Senior Resident, ${ }^{3,4}$ Junior Resident, ${ }^{1-4}$ Dept. of Ophthalmology, ${ }^{5}$ Dept. of Obstetrics and Gynecology, \\ Institute of Medical Sciences, Banaras Hindu University, Varanasi, Uttar Pradesh, India
}

*Corresponding Author:

Email: mauryarp_bhu@yahoo.com

\begin{abstract}
Aim: To determine the prevalence and pattern of retinal vascular disorders in pregnant women.

Materials and Methods: This hospital based, prospective observational study was conducted over a period of two years. Patients were selected from outpatient department and antenatal ward of Department of Obstetrics and Gynecology and outpatient department of Ophthalmology, SS Hospital, IMS, BHU, Varanasi. In all cases detailed obstetric history including age, gravida, gestational age, general and antenatal examination and relevant pathological investigations like blood sugar, blood urea, serum creatinine and urinary protein were carried out. After taking ocular history, detailed ocular examination including visual acuity and fundus examination under mydriasis with $1 \%$ tropicamide eye drop was carried out. All the findings were recorded on a data sheet and were analyzed using SPSS programme. The Chi-Square test was used to evaluate the association between the various antenatal factors and retinal vascular changes.

Results: Of 210 patients $38.09 \%$ patients were primigravida and $28.57 \%$ were second gravida. $28.57 \%$ had pregnancy induced hypertension (PIH), $13.33 \%$ had gestational diabetes mellitus, $12.38 \%$ had preexisting diabetes mellitus. Fundus abnormalities were observed in $110(52.38 \%)$ cases among them commonest retinal pathology was hypertensive retinopathy 38 (34.55\%) followed by diabetic retinopathy $(32.73 \%)$, retinal vein occlusion $(16.36 \%)$ and central serous chorioretinopathy $(7.27 \%)$. Out of 60 cases of PIH $38(63.33 \%)$ had retinal abnormalities. Retinal vascular disorders were seen in $>80 \%$ cases of severe preeclampsia and about $90 \%$ cases of eclampsia. Majority $(68.42 \%)$ of PIH patient had grade I hypertensive retinopathy. The commonest retinal change was arterial attenuation (28.57\%) followed by dot and blot hemorrhage (21.90\%), A-V crossing changes $(20.48 \%)$, hard exudates $(19.05 \%)$, flame shaped hemorrhage $(42.56 \%)$ and macular edema $(18.10 \%)$. However in $5.71 \%$ cases papilledema and in $5.24 \%$ cases ischemic optic neuropathy was observed

Conclusion: The most common vision threatening retinal vascular disorders in pregnancy was hypertensive retinopathy $(34.55 \%)$ followed by non proliferative diabetic retinopathy $(32.73 \%)$, pregnancy associated venous occlusive disorders of retina $(16.36 \%)$ and central serous chorioretinopathy (7.27\%). Other retinal abnormalities seen in pregnancy included optic neuritis, papilledema and macular edema. Pregnancy may be one of the risk factors for retinal vasculopathy and temporary visual impairment. Thus, ocular fundus examination may be a valuable and necessary routine investigative procedure in pregnancy.
\end{abstract}

Keywords: Diabetic retinopathy, Eclampsia, Hypertensive retinopathy, Ophthalmoscopy, Pre-eclampsia, Pregnancy induced retinal disorders.

\section{Introduction}

Pregnancy can cause changes in eyes of healthy women as well as in those having pre-existing systemic diseases like diabetes mellitus and hypertension. Ocular manifestations during pregnancy can be caused by physiological changes, pregnancy specific eye disorders and worsening of pre-existing retinal disorders. Retinal vascular abnormality during pregnancy mainly occurs as a result of haematologic, hormonal, metabolic and cardiovascular changes. ${ }^{1}$

The most common retinal vascular disorder altered by pregnancy is diabetic retinopathy (DR). Progression of diabetic retinopathy during pregnancy may be due to risk factors such as hypertension, obesity and poor glycemic control. Other retinal and chorioretinal disorders associated with pregnancy include central serous chorioretinopathy and occlusive vasculopathy such as retinal artery occlusion and retinal vein occlusion, most common sight threatening conditions. ${ }^{2-}$ ${ }^{5}$ During pregnancy thromboembolic events take place due to hypercoagulable states with an increase in thrombin levels, decrease in the levels of endogenous anticoagulants and venous stasis due to effect of progesterone on blood vessel walls. ${ }^{2,6}$ The increased risk of thromboembolic disorders during pregnancy may lead to occlusive vasculopathy. Pregnancy Induced Hypertension (PIH) is a specific cause of retinopathy which affects $5-10 \%$ of all pregnancy worldwide. ${ }^{7}$ Retinal involvement is common in PIH occurring in about $30-100 \%$ of patients. ${ }^{8}$

PIH is a hypertensive disorder of pregnancy that occurs after 20 weeks of gestation in the absence of other causes of raised blood pressure (> 140/90 mm of $\mathrm{Hg}$ ) associated with anasarca and or proteinuria ( $>300 \mathrm{mg} / 24 \mathrm{hrs}$ ). PIH with significant proteinuria is called Pre-eclampsia and when associated with convulsions or coma is called Eclampsia.

It has been reported that vision threatening retinal changes in patients with preeclampsia and eclampsia are acute ischemic optic neuropathy, central serous retinopathy, maculopathy, central retinal vein occlusion, retinal detachment and choroidal ischemia. ${ }^{9-}$ ${ }^{13}$ Inspite of wide spectrum of retinal lesions occurring in pregnancy very little study have been reported from 
North India. Therefore this study was done to determine the prevalence and pattern of retinal vascular disorders during pregnancy.

\section{Materials and Methods}

This hospital based, prospective, observational study was conducted jointly by Department of Ophthalmology and Obstetrics and Gynecology, S.S. Hospital, Institute of Medical Sciences, Banaras Hindu University, Varanasi between December 2016 and January 2018. Cases were randomly selected from antenatal clinic and wards of Department of Obstetrics and Gynecology and Ophthalmology OPD. All pregnant women willing to participate were included in this study. Patients who had history of ocular trauma, surgery, laser treatment and hazy ocular media were excluded from the study. The study was approved by Institute Ethical Committee.

After obtaining an informed consent, patients were thoroughly evaluated by an Obstetrician. Detailed antenatal history, general, physical and systemic examinations and relevant investigations like routine blood count, HIV, HBsAg, blood sugar, renal function test, TORCH profile and USG Abdomen etc. were carried out.

Detailed ocular history and examination like visual acuity, slit lamp biomicroscopy, Goldmann applanation tonometry and fundus examination under $1 \%$ tropicamide eye drop with direct ophthalmoscope in dark room were done in all patients. Fundus photographs were taken for documentation. Fundus findings such as changes in size, shape and color of disc, disc margin, cup:disc ratio, changes in caliber of retinal vessels, arterio-venous ratio, vascular blood column, AV crossings, changes in macular area and presence of hemorrhage, exudates etc. were recorded.

Keith - Wagener classification was used for grading the hypertensive retinopathy as below:

Grade 1: Mild generalized arterial attenuation, particularly of small branches;

Grade 2: More severe Grade 1 + focal arteriolar attenuation;

Grade 3: Grade $2+$ hemorrhages, hard exudates, cotton wool spots;

Grade 4: Grade 3 + optic disc swelling.

Data collected were analyzed using SPSS software version 18. Chi-Square test was applied. P-value $<0.05$ was considered statistically significant.

\section{Results}

Maximum number of patients (57.14\%) belonged to age group 21-25 years. (Table 1)
Table 1: Age wise distribution of study subjects

\begin{tabular}{|l|c|c|}
\hline \multicolumn{1}{|c|}{ Age in years } & Number & Percentage \\
\hline Upto 20 & 38 & 18.10 \\
\hline $21-25$ & 120 & 57.14 \\
\hline $26-30$ & 22 & 10.48 \\
\hline $31-35$ & 20 & 9.52 \\
\hline$>35$ & 10 & 4.76 \\
\hline Total & 210 & \\
\hline
\end{tabular}

Out of total 210 patients examined, 52.38\% had retinal disorder. The mean age was $24.58 \pm 2.46$ year (range 18-43 years). The gestational period ranged between 20-37 weeks. 80 women $(38.10 \%)$ were primigravida, $60(28.57 \%)$ were second gravida and 37 $(17.62 \%)$ were third gravida. In primigravida and second gravida about $53 \%$ had retinal disorders while $80 \%$ of fifth gravida and $56 \%$ of fourth gravida had retinal disorder.

Table 3 shows that pregnancy induced hypertension (PIH) was found in $60(28.57 \%)$ patients, gestational diabetes in $28(13.33 \%)$, pre-existing diabetes in $26(12.35 \%)$ and pre-existing hypertension in16 $(7.82 \%)$ while rest were normal.

Out of $210(52.35 \%)$ patients $110(52.38 \%)$ had retinal disorders, $34.55 \%$ had hypertensive retinopathy, $32.73 \%$ had diabetic retinopathy, $16.36 \%$ had retinal vein occlusion, $7.27 \%$ had central serous chorioretinopathy and $5.45 \%$ had ischemic optic neuropathy.(Table 4, Fig. 1-8)

Table 2: Distribution according to number of gravida and retinal abnormality

\begin{tabular}{|l|c|c|}
\hline Gravida & Number & Retinal abnormality \\
\hline Primi & 80 & $43(53.75 \%)$ \\
\hline Second & 60 & $32(53.33 \%)$ \\
\hline Third & 37 & $16(43.24 \%)$ \\
\hline Fourth & 18 & $10(55.56 \%)$ \\
\hline Fifth & 10 & $8(80.00 \%)$ \\
\hline Onwards & 5 & $3(60.00 \%)$ \\
\hline
\end{tabular}

Table 3: Distribution according to antenatal conditions

\begin{tabular}{|l|c|c|}
\hline \multicolumn{1}{|c|}{ Status } & Number & Percentage \\
\hline Normal & 80 & 38.09 \\
\hline Pre-existing DM & 26 & 12.38 \\
\hline Pre-existing HTN & 16 & 7.61 \\
\hline PIH & 60 & 28.57 \\
\hline Gestational DM & 28 & 13.33 \\
\hline Total & 210 & \\
\hline
\end{tabular}

Table 4: Distribution according to retinal pathology (N=110)

\begin{tabular}{|l|c|c|}
\hline \multicolumn{1}{|c|}{ Retinal Pathology } & Number & Percentage \\
\hline Hypertensive retinopathy & 38 & 34.55 \\
\hline Diabetic retinopathy & 36 & 32.73 \\
\hline Retinal vein occlusion & 18 & 16.36 \\
\hline Central serous retinopathy & 8 & 7.27 \\
\hline Optic neuropathy & 6 & 5.45 \\
\hline Others & 4 & 3.64 \\
\hline
\end{tabular}




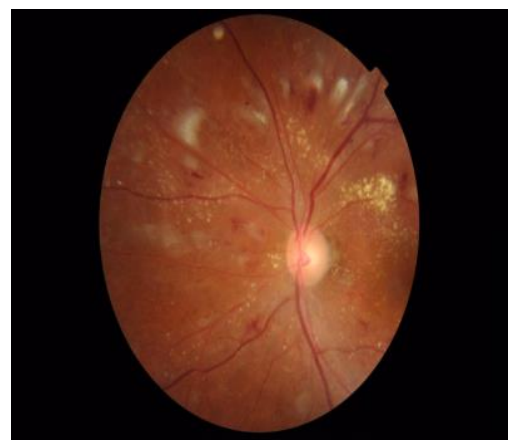

Fig. 1: Fundus photograph of left eye showing features of Grade 4 Hypertensive Retinopathy

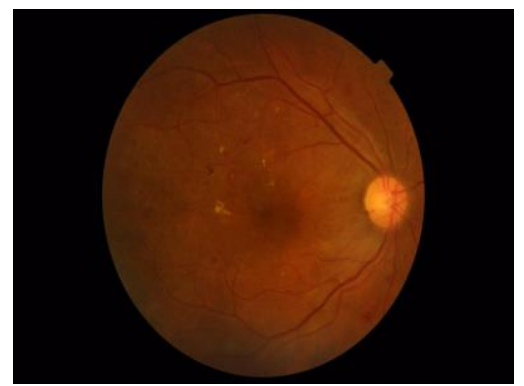

Fig. 2: Fundus photograph of Right Eye showing features of Mild Non-Proliferative Diabetic Retinopathy ( NPDR)

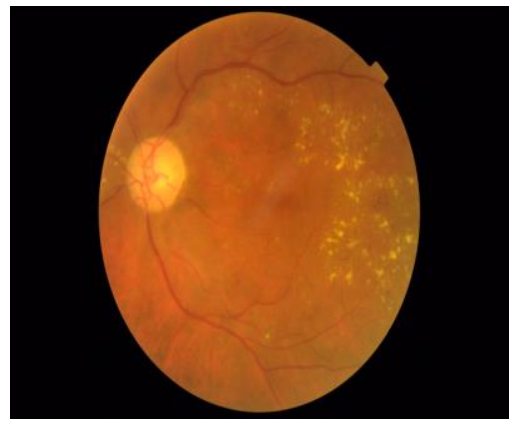

Fig. 3: Fundus photograph of Right Eye showing features of Moderate Non-Proliferative Diabetic Retinopathy (NPDR) with Cystoids Macular Edema (CME)

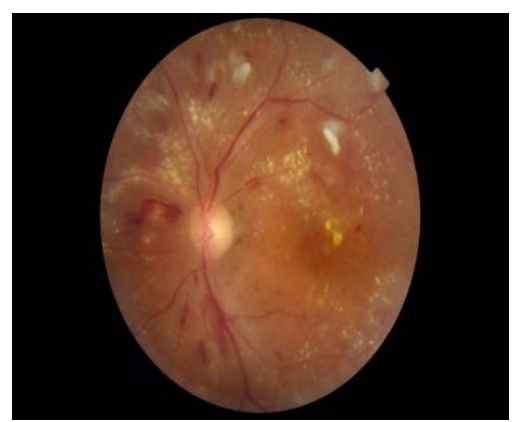

Fig. 4: Fundus photograph of Left Eye showing features of very Severe Non-Proliferative Diabetic
Retinopathy (NPDR) with Cystoids Macular Edema (CME)

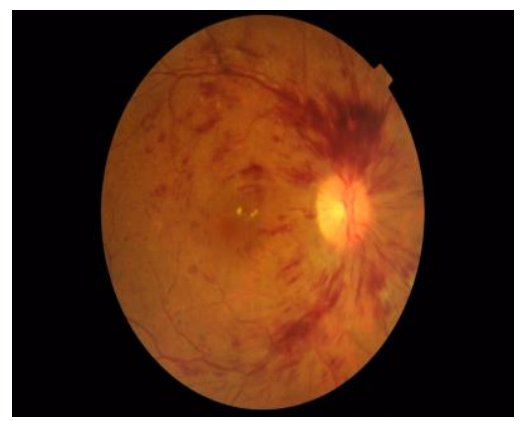

Fig. 5: Fundus photograph of Right Eye showing features of Central Retinal Vein Occlusion (CRVO)

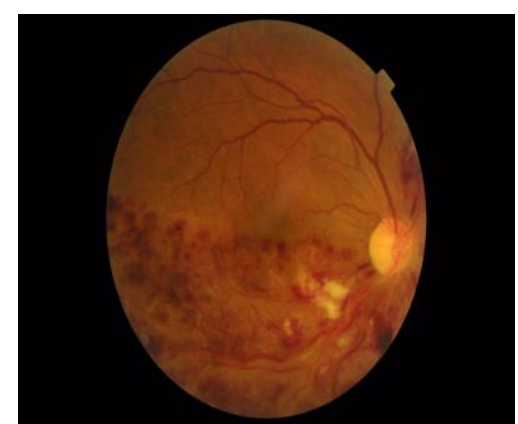

Fig. 6: Fundus photograph of Right Eye showing features of Inferotemporal Branch Retinal Vein Occlusion ( BRVO)

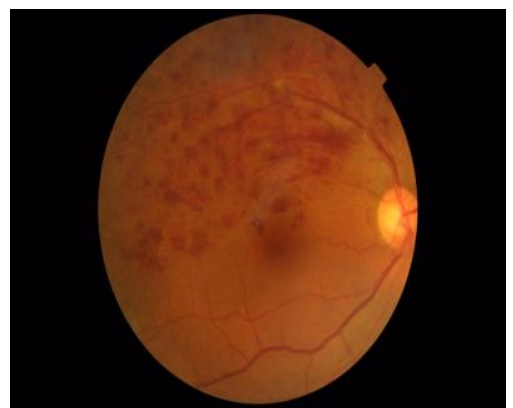

Fig. 7: Fundus photograph of Right Eye showing features of Superotemporal Branch Retinal Vein Occlusion (BRVO)

No retinal changes were seen in $47.62 \%$ of the patients. The commonest retinal change was arterial attenuation $(28.57 \%)$ followed by dot and blot haemorrhage $(21.90 \%), \quad A-V$ crossing changes $(20.48 \%)$, hard exudates $(19.05 \%)$, flame shaped haemorrhage $(42.56 \%)$ and macular edema (18.10\%). However in $5.71 \%$ cases papilledema and in $5.24 \%$ cases ischemic optic neuropathy was observed. (Table $5)$. 
Table 5: Distribution according to fundus findings $(\mathrm{N}=\mathbf{2 1 0})$

\begin{tabular}{|l|c|c|}
\hline \multicolumn{1}{|c|}{ Fundus Findings } & Number & Percentage \\
\hline Normal & 100 & 47.62 \\
\hline Arterial attenuation & 60 & 28.57 \\
\hline AV crossing changes & 43 & 20.48 \\
\hline Flame shaped haemorrhage & 90 & 42.56 \\
\hline Dot and blot haemorrhage & 46 & 21.90 \\
\hline Pre-retinal haemorrhage & 06 & 2.86 \\
\hline Hard exudates & 40 & 19.05 \\
\hline Cotton wool spots & 32 & 15.24 \\
\hline Papilledema & 12 & 5.71 \\
\hline Retinal edema & 22 & 10.48 \\
\hline Optic neuropathy & 11 & 5.24 \\
\hline Macular edema & 38 & 18.10 \\
\hline Retinal detachment & 4 & 1.90 \\
\hline
\end{tabular}

In our study, out of 60 cases of PIH 38(63.33\%) had retinal abnormality. Retinal vascular disorders were seen in more than $80 \%$ cases of severe pre-eclampsia and about $90 \%$ cases of eclampsia. (Table 6)

Table 6: Distribution according to number of PIH cases and retinal abnormality

\begin{tabular}{|l|c|c|}
\hline \multicolumn{1}{|c|}{ Type of PIH } & $\begin{array}{c}\text { Number } \\
\text { of cases }\end{array}$ & $\begin{array}{c}\text { No. of cases with } \\
\text { retinal disorders }\end{array}$ \\
\hline Gestational hypertension & 2 & 0 \\
\hline Mild pre-eclampsia & 24 & $9(37.50 \%)$ \\
\hline Severe pre-eclampsia & 16 & $13(81.25 \%)$ \\
\hline eclampsia & 18 & $16(88.89 \%)$ \\
\hline others & 0 & 0 \\
\hline total & 60 & $38(63.33 \%)$ \\
\hline
\end{tabular}

Out of 38 cases of hypertensive retinopathy, $26(68.42 \%)$ had grade I hypertensive retinopathy, $8(21.05 \%)$ had grade II hypertensive retinopathy while $4(10.53 \%)$ had grade III hypertensive retinopathy. (Table 7 )

Table 7: Grade of hypertensive retinopathy in our patients

\begin{tabular}{|l|c|c|}
\hline \multicolumn{1}{|c|}{ Grade } & Number & Percentage \\
\hline I & 26 & 68.42 \\
\hline II & 8 & 21.05 \\
\hline III & 4 & 10.53 \\
\hline IV & 0 & 0 \\
\hline Total & 38 & 100.0 \\
\hline
\end{tabular}

\section{Discussion}

The vision threatening conditions in pregnancy are not uncommon. Though, hypertensive disorders in pregnancy is a major health issue in developing countries responsible for both maternal and fetal mortality but eyes are rarely examined unless serious complications like severe pre-eclampsia or eclampsia occurs.

In our study, the incidence of PIH as well as retinal changes is more common in age group of 21-25 years. Similar findings were reported in study of Bakhada $\mathrm{RN}^{14}$ Neutra RR reported that women under 20 years were six to seven times more susceptible than those in age $25-29$ years. ${ }^{15}$

In the present study, overall positive fundus findings were seen in $52.35 \%$ cases. Reddy ${ }^{16}$ also reported overall positive fundus finding in 59\% cases. Tadin et al $^{17}$ from Croatia reported $45 \%$ of retinal changes in their study of 40 cases of PIH, but Karki et $\mathrm{al}^{18}$ from Nepal reported $13.7 \%$ of positive fundus changes in their study of 153 subjects.

The incidence of PIH is more common in primigravida or second gravida because young arterioles are more sensitive to high blood pressure. ${ }^{14}$

In this study hypertensive retinopathy changes were seen in $34.55 \%$ cases. Most of the hypertensive retinal changes were grade I or grade II retinopathy changes. Ranjan $\mathrm{R}$ et $\mathrm{al}^{19}$ reported hypertensive retinopathy changes in $40 \%$ of patients with PIH. Majority of them were grade I retinopathy. The progression of retinal vascular changes and retinal edema is suggestive of severity of PIH. ${ }^{14,20,21}$

In our study $36(17.14 \%$ ) cases had retinal findings suggestive of diabetic retinopathy and $16.36 \%$ had retinal vein occlusion. $13.33 \%$ patients had gestational diabetes mellitus and $12.35 \%$ had pre-existing diabetes mellitus. The gestational diabetes and pre-existing diabetes mellitus may deteriorate during pregnancy. DM in pregnancy may lead to development of retinal vein occlusion $(\mathrm{RVO}){ }^{1,22}$

The commonest retinal changes noted were arterial attenuation $(28.57 \%)$ followed by dot and blot haemorrhage $(21.90 \%)$, AV crossing changes $(20.45 \%)$ and macular edema $(18.10 \%)$. However, $1.90 \%$ cases had retinal detachment. Fry et $\mathrm{al}^{23}$ reported retinal 
detachment in $1.20 \%$ cases. Bosco et $\mathrm{al}^{24}$ reported bilateral retinal detachment in 7 cases.

The presence of retinal haemorrhage, macular edema, papilledema and retinal detachment are the indications of termination of pregnancy to save mother and child. ${ }^{25}$

\section{Conclusion}

The most common vision threatening retinal vascular disorders in pregnancy was hypertensive retinopathy $(34.55 \%)$ followed by non proliferative diabetic retinopathy $(32.73 \%)$, pregnancy associated venous occlusive disorders of retina $(16.36 \%)$ and central serous chorioretinopathy $(7.27 \%)$. Other retinal abnormalities seen in pregnancy included optic neuritis, papilledema and macular edema. Pregnancy may be one of the risk factors for retinal vasculopathy and temporary visual impairment. Thus, ocular fundus examination may be a valuable and necessary routine investigative procedure in pregnancy.

\section{Funding Support: None \\ Conflict of Interests: No conflict of interest}

\section{References}

1. Gray G, Nelson-Piercy C. Thromboembolic disorders in obstetrics. Best practice \& research Clinical obstetrics \& gynaecology. 2012;26(1):53-64. pmid:22115745.

2. Errera MH, Kohly RP, da Cruz L. Pregnancy-associated retinal diseases and their management. Surv Ophthalmol. 2013;58(2):127-42. Epub 2013/02/16. S00396257(12)00181-6 [pii].doi: 10,1016/j,survophthal.2012.08.001 pmid:23410822.

3. Hayreh SS. Prevalent misconceptions about acute retinal vascular occlusive disorders. Prog Retin Eye Res. 2005;24(4):493-519. Epub 2005/04/23.doi 10.1016/j.preteyres. 2004. 12. 001 PMID: 15845346.

4. McIntosh RL, Rogers SL, Lim L, Cheung N, Wang JJ, Mitchell P, et al. Natural history of central retinal vein occlusion: an evidence-based systematic review. Ophthalmology. 2010;117(6):1113-23 e15. Epub 2010/05/01. S0161-6420(10)00133-8 [pii].doi: 10.1016/j.ophtha.2010.01.060 PMID:20430446.

5. Rogers SL, McIntosh RL, Lim L, Mitchell P, Cheung N, Kowalski JW, et al. Natural history of branch retinal vein occlusion: an evidence-based systematic review. Ophthalmology. 2010;117(6):1094-101 e5. Epub 2010/05/01. S0161-6420(10)00131-4 [pii]. doi: 10.1016/j.ophtha.2010.01.058 PMID:20430447

6. Kamel H, Navi BB, Sriram N, Hovsepian DA, Devereux RB, Elkind MS. Risk of a Thrombotic Event after the 6Week Postpartum Period. N Engl J Med. 2014. Epub 2014/02/15. doi: 10.1056/NEJMoa1311485 PubMed PMID: 24524551.

7. Report of the confidential enquiries into maternal deaths in Malaysia.2005. Ministry of Health Malaysia.

8. Hallum AV. Eye changes in hypertensive toxaemia of pregnancy. A study of 300 cases. J Am Med Assoc 1936;106:1649-51.

9. Beck RW, Gamel JW, Wilcourt RJ, et al. Acute ischemic optic neuropathy in severe preeclampsia. Am J Ophthalmol 1980;90:342-46.

10. Day H, Burns J, Bosio P. A case of bilateral serous retinal detachments in severe pre-eclampsia. J Obstet Gynaecol 2008; 28:534-35.
11. Rahman I, Saleem G, Semple D, et al. Preeclampsia resulting in central retinal vein occlusion. Eye 2006; 20:955-57.

12. Lara-Torre E, Lee MS, Wolf MA, et al. Bilateral retinal occlusion progressing to long-lasting blindness in severe preeclampsia. Obstet Gynecol 2001;100:940-42.

13. Ramaesh K, Nagendran S, Saunders DC. Choroidal ischaemia and serous retinal detachment in toxaemia of pregnancy. Eye 1999; 13:795-96.

14. Bakhda RN. Clinical study of fundus findings in pregnancy induced hypertension. J Family Med Prim Care 2016;5:424-9.

15. Neutra RR. A case-control study for estimating the risk of eclampsia in California, Colombia. Am J Obstet Gynecol 1973;117:894.

16. Reddy SC. Ocular fundus changes in toxemia of pregnancy.The Antiseptic 1989;86(7):367-72.

17. Tadin I, Bojic L, Mimica M, Karelovic D, Dogas Z. Hypertensive retinopathy and preeclampsia.Coll Antropol 2001;25(Suppl 0);77-81.

18. Karki P, Malla KP, Das H, Uprety DK. Association between pregnancy induced hypertensive fundus changes and fetal outcome.Nepal J Ophthalmol 2010;2(1):26-30.

19. Ranjan R, Sinha S, Seth S. Fundus Changes and Fetal Outcomes in Pregnancy Induced Hypertension: An Observational Study. Int J Sci Stud 2014;2(7):6-9.

20. Fry W. Extensive bilateral retinal detachment in eclampsia with complete reattachment: Report of two cases. Arch Ophthalmol 1929;1:609-14.

21. Mabie WC, Ober RR. Fluorescein angiography in toxaemia of pregnancy. Br J Ophthalmol 1980;64:666-71.

22. Ferrara A. Increasing prevalence of gestational diabetes mellitus: a public health perspective. Diabetes Care.2017;30 Suppl 2:S141-6. Epub 2007/07/13. Doi: 10.2337/dc07-s206 PMID: 17596462.

23. Fry WE. Extensive bilateral retinal detachment in eclampsia with complete reattachment. Report of two cases. Arch Ophthalmol 1929;1:609-14.

24. Bosco JA. Spontaneous nontraumatic retinal detachment in eclampsia without hypertensive retinopathy. Am J Ophthalmol 1980;90:792-6.

25. Reddy SC. Raghavamma TV. Retinal detachment in preeclampsia-A Case report. J Obset Gynaec of India. 1981;31(3):501-3. 